\title{
VHF radar studies of counter electrojet events during the northern winter solstice period of 1992
}

\author{
G. Manju and K. S. Viswanathan \\ Space Physics Laboratory, Vikram Sarabhai Space Centre, Trivandrum - 695 022, Kerala, India \\ (Received September 7, 2006; Revised December 21, 2006; Accepted December 21, 2006; Online published May 7, 2007)
}

\begin{abstract}
A sequence of counter electrojet events during the winter solstice period of 1992 are studied along with control quiet day observations at the magnetic equatorial location of Trivandrum $\left(8.5^{\circ} \mathrm{N}, 76.5^{\circ} \mathrm{E}\right.$; dip $\left.0.5^{\circ} \mathrm{N}\right) \mathrm{using} \mathrm{VHF}$ (54.95 MHz) coherent backscatter radar observations. Some of the unusual features observed on these days are: (1) an unusual radar signal with reversed Doppler values corresponding to westward electric field, for a brief duration of $5 \mathrm{~min}$ at approximately $1330 \mathrm{~h}$, at the higher altitudes 112-117 km on 21 January 1992, as against the usual observation of the signal at lower altitudes below $112 \mathrm{~km}$ during CEJ times; (2) type I plasma waves in the late afternoon around $1800 \mathrm{~h}$ (after the CEJ event) at altitudes above $101 \mathrm{~km}$ (on 21 and 23 January 1992) when the backscattered power is low, indicating the unusual tidal influences on the electric field behavior on certain CEJ days; (3) distortions in the height structure of the vertical polarization electric field, attributed to the modulation of the electrojet altitude structure by action of zonal neutral winds; (4) westward electric field, as seen by the radar, even while the $\Delta \mathrm{H}$ values are positive.
\end{abstract}

Key words: Equatorial electrojet, counter electrojet, ionospheric irregularities.

\section{Introduction}

One of the most important aspects of the equatorial electrojet is the reversal of the normal eastward flow of current during the morning (0600-0800 LT) and afternoon hours (1400-1730 LT) observed on some magnetically quiet days. This reversal to a westward current, as indicated by the horizontal component of the geomagnetic field, going below its nighttime level is referred to as the counter electrojet (CEJ). On certain days, the $\mathrm{H}$ value decreases to less than its normal value although it still remains above the nighttime level; this behavior is termed a partial counter electrojet event. Several morphological studies on CEJ events have been made in the past (Rastogi, 1974, 1989; Mayaud, 1977; Reddy, 1977, 1981, 1989; Forbes, 1981 and references therein).

With the advent of VHF and HF coherent backscatter radars, many workers (Crochet et al., 1979; Viswanathan, 1986; Somayajulu and Viswanathan, 1987; Somayajulu et al., 1994) have studied the reversed electric field during CEJ events. Somayajulu et al. (1994) presented simultaneous observations made near the magnetic equator during CEJ events using radar, magnetometer and ionosonde data, wherein they provided experimental evidence of the theoretically predicted distortions in the altitude structure of the vertical polarization electric field $\left(E_{z}\right)$. Theoretical studies carried out to gain an understanding of the physical processes underlying the CEJ phenomenon have used two different approaches. In one approach, the reversal of the global east-west electric field $\left(E_{y}\right)$ in the equato-

Copyright (c) The Society of Geomagnetism and Earth, Planetary and Space Sciences (SGEPSS); The Seismological Society of Japan; The Volcanological Society of Japan; The Geodetic Society of Japan; The Japanese Society for Planetary Sciences; TERRAPUB. rial electrojet (EEJ) due to a combination of global scale tidal wind modes has been shown to produce a CEJ event in the late afternoon hours only (Schieldge et al., 1973; Forbes and Lindzen, 1976; Marriot et al., 1979; Hanuise et al., 1983). The two-dimensional computations of Stening (1977a, b) also indicate that the semidiurnal tidal modes are capable of generating CEJ events. Somayajulu (1988) has shown that the amplitudes and phases of the diurnal and semi-diurnal components of $\mathrm{H}$ on CEJ days are different from those on normal electrojet days. In the second approach, the possible reversal of $E_{z}$ in the entire altitude range of the EEJ due to local interaction of (assumed) height-varying winds has been considered (Richmond, 1973a; Fambitakoye et al., 1976; Reddy and Devasia, 1981; Anandarao and Raghavarao, 1987 and references therein). The role of the return currents of the EEJ, in producing counter electrojet effects has been examined by Onwumechili (1992). Further, the role of height-varying winds as an important source of the EEJ return currents has also been discussed.

In the present work, the 54.95-MHz VHF backscatter radar observations corresponding to $2.7-\mathrm{m}$ scale size fieldaligned irregularities, that were made prior to, and during and after the CEJ events on magnetically quiet days are presented. In the equatorial electrojet region, two types of plasma waves, type I and type II, are observed. Type I waves are attributed to the two-stream instability mechanism (Farley, 1963) and type II waves to the gradient drift instability mechanism (Reid, 1968). The type I irregularities are characterized by phase velocities nearly equal to the ion-acoustic velocity $\left(C_{s}\right)$ of the medium and appear more or less simultaneously at all radar elevation angles when the threshold condition is exceeded (Farley, 1985). For type I 
waves, the observed phase velocity is independent of the zenith angle, while for type II waves, it shows a cosine $\theta$ dependence (where $\theta$ is the elevation angle). Type II irregularities have phase velocities proportional to the electron drift velocity and are observed even for very small electron drifts; whenever the electron density gradient and the electric field are in the same direction. Type I spectra are very nearly Gaussian, narrow and the Doppler frequencies are high. Type II spectra are skewed and generally broad. When the electrojet is strong, spectra are mostly type I. The presence of type I waves is identified by the appearance of a well-defined peak in the spectrum close to the ion-acoustic velocity of the medium (Ravindran and Reddy, 1993). Type I spectra are generally seen at the higher EEJ altitudes $(>100 \mathrm{~km})$, while type II spectra are seen at lower altitudes below $(100 \mathrm{~km})$, when composite spectra are observed. In addition to radar data, the magnetic field variations at Trivandrum have also been examined for the days of study.

\section{Experimental set-up}

The study has been carried out using VHF backscatter radar observations at the magnetic equatorial location of Trivandrum $\left(0.5^{\circ} \mathrm{N}\right)$. Detailed specifications, data recording and the analysis procedure for VHF backscatter radar (operating at $54.95 \mathrm{MHz}$ ) has been described in Reddy et al. (1987). The parameters estimated from the radar Doppler spectra are the power (zeroth moment); mean Doppler frequency (first moment) and the width of the spectrum (second moment). The power is a measure of the strength of the scattering centers present in the volume illuminated by the radar; mean Doppler frequency gives the mean drift velocity of the irregularities; the width of the spectrum is a gross indicator of the strength of turbulence. For the Trivandrum radar geometry, a negative (positive) Doppler shift corresponds to the westward (eastward) drift of irregularities in the presence of an eastward (westward) electric field (Reddy et al., 1987). The expressions for the drift velocities and electric field are given as:

The line of sight velocity of the irregularities,

$$
V_{p}=(\lambda / 2) \bar{f}_{D}
$$

where $\lambda$ is the radar wavelength, $\bar{f}_{D}$ is the mean Doppler frequency. The E-W electron drift velocity,

$$
\begin{aligned}
V_{e y} & =\left(V_{p}\right) / \cos (\theta) \\
E_{y} & =V_{e y}(1+\alpha) B / \rho_{i}
\end{aligned}
$$

where $E_{y}$ is the global E-W electric field and $B$ is the geomagnetic field.

$$
\rho_{i}=\left(v_{i} / \Omega_{i}\right)
$$

where $v_{i}$ and $v_{e}$ are the ion and electron collision frequencies, and $\Omega_{i}$ and $\Omega_{e}$ are the ion and electron gyro frequencies, $\alpha=\frac{v_{i} v_{e}}{\Omega_{i} \Omega_{e}}$. The vertical polarization electric field,

$$
E_{z}=V_{e y} B
$$

The horizontal component of the earth's magnetic field is obtained from a flux gate magnetometer operated at Trivandrum by the Indian Institute of Geomagnetism (IIG), Bombay.

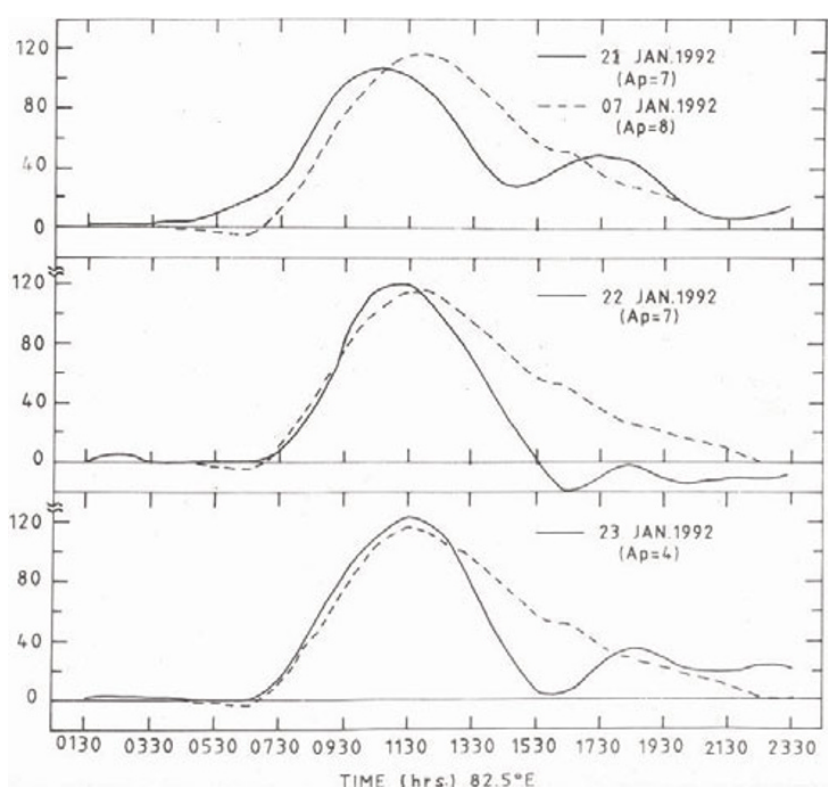

Fig. 1. Time variations of $\Delta \mathrm{H}$ on three quiet CEJ days of 21,22 and 23 January 1992 along with the control quiet day variations on 07 January 1992. The control day variations are shown in each panel as a dashed curve.

\section{Results}

In this section, the radar observations made during a sequence of CEJ events in the International Equatorial Electrojet Year (IEEY) observational campaign of January 1992 are presented along with the magnetic field variations.

\subsection{Daytime variation of $\triangle \mathrm{H}$ on CEJ days}

Figure 1 shows the time variations of $\Delta \mathrm{H}$ values (deviations in the horizontal component $\mathrm{H}$ of the earth's magnetic field strength from its average value over 0000-0400 IST) at Trivandrum during three CEJ days of 21 January $\left(A_{p}=7\right)$, 22 January $\left(A_{p}=7\right)$ and 23 January $\left(A_{p}=4\right), 1992$ (shown as solid line curves in the three panels of the figure). In all figures, IST refers to Indian Standard Time corresponding to $82.5^{\circ} \mathrm{E}$ longitude. For comparison, $\Delta \mathrm{H}$ variations on the control quiet day of 07 January $1992\left(A_{p}=8\right)$ are shown (as dashed line) in the same figure in all the panels.

On the control day (without CEJ effects) of 07 January 1992, the magnetic field variations exhibit the usual increase (in $\Delta \mathrm{H}$ ) in the morning hours, reach a peak value of $\sim 115 \mathrm{nT}$ around $1130 \mathrm{~h}$, then decrease gradually and reach the night-time level by $\sim 2230 \mathrm{~h}$. This is typical of the quiet day $\Delta \mathrm{H}$ variations at the equatorial location of Trivandrum. The $\Delta \mathrm{H}$ variations on the partial CEJ day (wherein $\Delta \mathrm{H}$ values show a depression and do not become negative with respect to the average night-time level) of 21 January, 1992 (top panel) show the usual increase up to $1030 \mathrm{~h}$. The peak value of $\Delta \mathrm{H}$ is $106 \mathrm{nT}$. This is followed by a decrease until $\Delta \mathrm{H}$ attains a minimum of about $25 \mathrm{nT}$ around $1430 \mathrm{~h}$. On this day, $\Delta \mathrm{H}$ values start increasing from the night-time level at $0330 \mathrm{~h}$. The $\Delta \mathrm{H}$ values after attaining a minimum value around $1430 \mathrm{~h}$ recover from the depression by $1600 \mathrm{~h}$ and thereafter show an increase, before falling again around $1830 \mathrm{~h}$.

On the CEJ day of 22 January, 1992 (middle panel) the $\Delta \mathrm{H}$ values show the morning increase from $0700 \mathrm{~h}$, attain a 


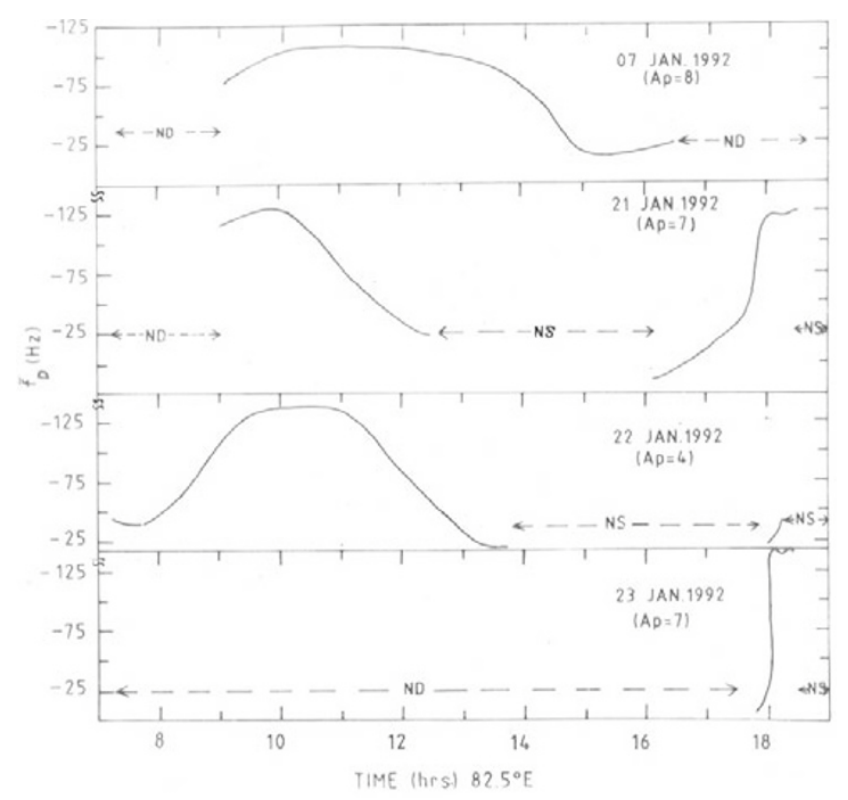

Fig. 2. Daytime variations of mean Doppler frequency $\left(\bar{f}_{D}\right)$ obtained at $104 \mathrm{~km}$ for the days shown in Fig. 1. Note the presence of type I irregularities as evidenced by high $\bar{f}_{D}$ values around $1800 \mathrm{~h}$ on 21 January 1992.

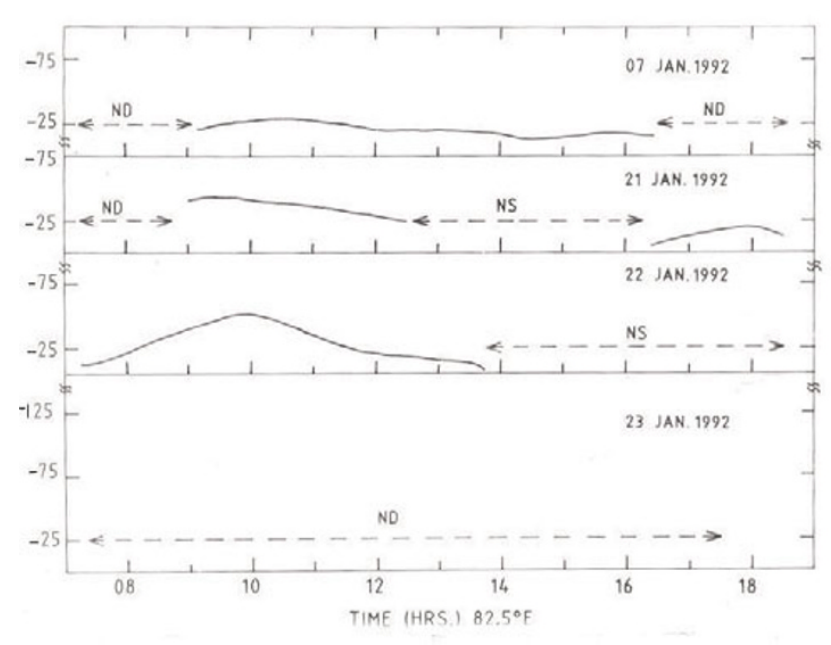

Fig. 3. Same as Fig. 2 but for $99 \mathrm{~km}$.

peak value of $120 \mathrm{nT}$ at $1130 \mathrm{~h}$, thereafter falling off steeply to below the night-time level at $1530 \mathrm{~h}$. The maximum negative value of $20 \mathrm{nT}$ is observed at $1630 \mathrm{~h}$. The field recovers to the night-time level by $1830 \mathrm{~h}$ and again decreases beyond that time.

On the other partial CEJ day of 23 January, 1992 (bottom panel) $\Delta \mathrm{H}$ values start increasing from $0630 \mathrm{~h}$, reach a peak value of $120 \mathrm{nT}$ at $1130 \mathrm{~h}$ and then fall off steeply to attain values close to the night-time level around $1600 \mathrm{~h}$. After the depression, $\Delta \mathrm{H}$ values show an increase similar to that observed on 23 January 1992, also as in the case of 21 January 1992.

On 21 January 1992, one notable feature is that $\Delta \mathrm{H}$ values start increasing from night time level as early as $0330 \mathrm{~h}$, unlike the usual increase from $\sim 0630 \mathrm{~h}$ on 21 January 1992. The peak in $\Delta H$ is attained earlier on the

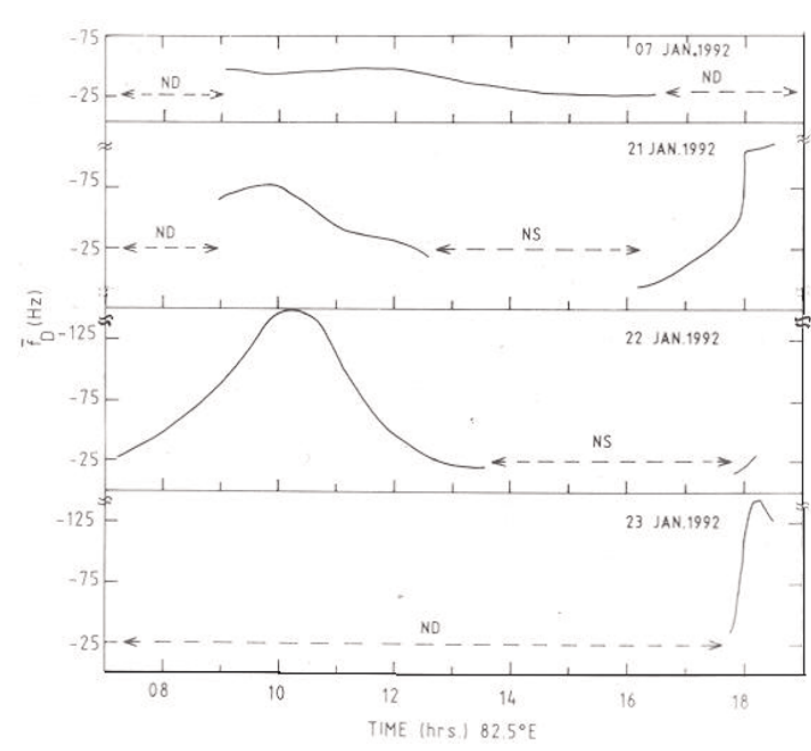

Fig. 4. Same as Fig. 2 but for $101 \mathrm{~km}$.

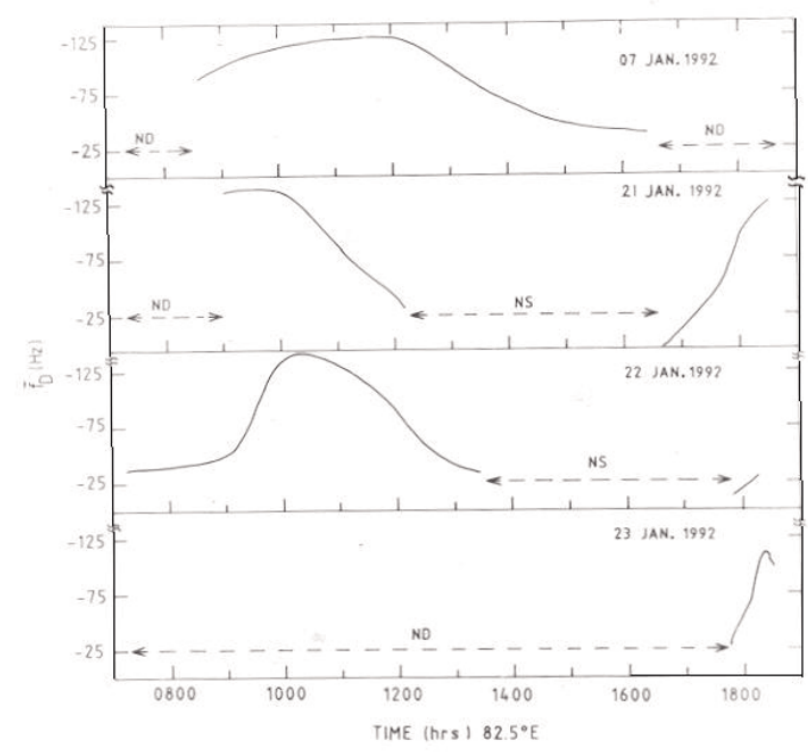

Fig. 5. Same as Fig. 2 but for 107 km.

CEJ days than on the control day. The $\Delta \mathrm{H}$ variations show a depression and thereafter increase on 21 and 23 January 1992.

3.2 Daytime variations of VHF radar measured $\bar{f}_{D}$ values on CEJ days

Figure 2 shows the time variations of the mean Doppler frequency $\left(\bar{f}_{D}\right)$ of the $2.7-\mathrm{m}$ scale size electron density irregularities at $104 \mathrm{~km}$ (which is close to the EEJ peak altitude) measured with the coherent VHF backscatter radar for the days shown in Fig. 1. The variations in $\bar{f}_{D}$ for the other altitudes of 99, 101 and $107 \mathrm{~km}$ are also shown in Figs. 3, 4 and 5, respectively. At the radar operating frequency of $54.95 \mathrm{MHz}$, the Doppler shift of $1 \mathrm{~Hz}$ corresponds to the line-of-sight (along the radar antenna beam direction which is towards the west) velocity of $2.7 \mathrm{~m} \mathrm{~s}^{-1}$. The $\bar{f}_{D}$ values shown here are the hourly averaged values during the times 
07 JAN.92 (Ap=8) $104 \mathrm{~km}$
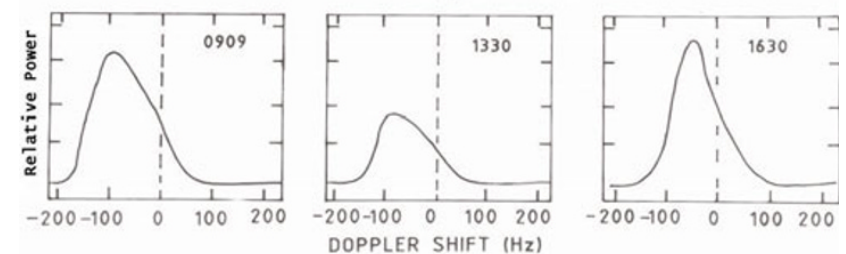

Fig. 6. Sample VHF Doppler spectra observed at 0909, 1330 and $1630 \mathrm{~h}$ for $104 \mathrm{~km}$ on 07 January 1992.

21 JAN. $1992(A p=7) 104 \mathrm{~km}$.
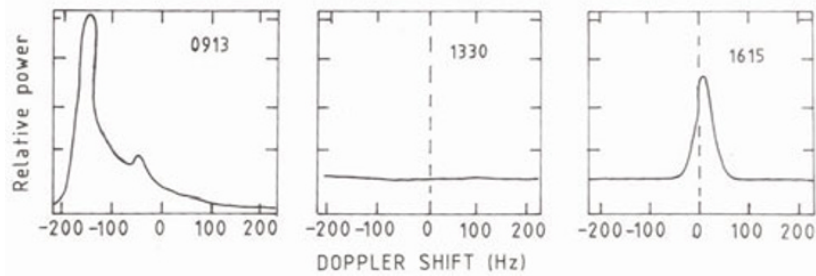

Fig. 7. Same as Fig. 6 but for 21 January 1992 at 0913, 1330 and 1615 $\mathrm{h}$. Note in particular the absence of signal at $1330 \mathrm{~h}$ and the reversed (positive) near Gaussian Doppler spectrum at $1615 \mathrm{~h}$.

when no significant fluctuations are seen in the backscattered Doppler values. At other times of the CEJ event duration (when the westward electric field $-E_{y}$ was present, corresponding to the radar observed $+\bar{f}_{D}$ values) and also at times after the CEJ event, the $\bar{f}_{D}$ values are plotted in the figures at $\sim 5$-min intervals, unless otherwise stated. The $\bar{f}_{D}$ values for all of the days and all heights are plotted as described above. The error in $\bar{f}_{D}$ computation is within \pm 1 Hz.

The time variations of $\bar{f}_{D}$ on the control day of 07 January 1992, shown in the top panel of Fig. 2, clearly depict the behavior of the quiet day electric field (eastward), increasing up to $1030 \mathrm{~h}$ (typically about $0.6 \mathrm{mV} / \mathrm{m}$ ). It can be seen from the figure that $\bar{f}_{D}$ attains a peak value of around $-115 \mathrm{~Hz}$ with a broad maximum that persists up to $\sim 1200$ $\mathrm{h}$ and thereafter decreases to a small $\bar{f}_{D}$ value at $1500-1600$ $\mathrm{h}$. In the figure, ND indicates no data, and NS indicates no signal condition.

On 21 January 1992 (second panel from top), $\bar{f}_{D}$ increases and attains a peak value of approximately $-125 \mathrm{~Hz}$ at $1000 \mathrm{~h}$. It thereafter falls off, reaching a value of -25 $\mathrm{Hz}$ at $1230 \mathrm{~h}$ before the radar signal disappears. The signal again appears at $\sim 1607 \mathrm{~h}$ with a westward electric field (corresponding to $+\bar{f}_{D}$ values of about $10 \mathrm{~Hz}$ ). Later, $\bar{f}_{D}$ values became negative gradually with time (corresponding to eastward electric field). The values increase to about $-125 \mathrm{~Hz}$ at $1800 \mathrm{~h}$, which corresponds to the presence of type I irregularities (Ravindran and Reddy, 1993). This indicates a larger eastward electric field at these times (quite comparable to the daytime $+E_{y}$ magnitude), even though $\Delta \mathrm{H}$ values are close to zero. This field of higher $E_{y}$ magnitude continues until $\sim 1830 \mathrm{~h}$ and thereafter the radar signal disappears. On the CEJ day of 22 January 1992 (third panel from top), the $\bar{f}_{D}$ increases up to $1000 \mathrm{~h}$, reaches a peak value of $\sim 135 \mathrm{~Hz}$ and starts falling off by $1100 \mathrm{~h}$. It reaches

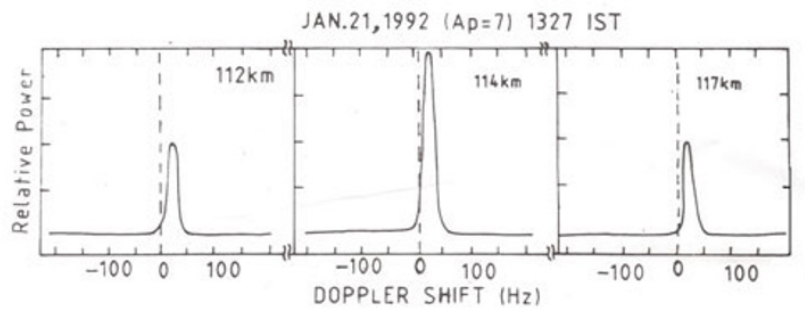

Fig. 8. Sample VHF reversed Doppler spectra (corresponding to westward electric field presence) observed on 21 January 1992 at $1327 \mathrm{~h}$ for the altitudes of 112, 114 and $227 \mathrm{~km}$. The spectra are neat and Gaussian in shape.

a low value at $\sim 1345 \mathrm{~h}$, and then the signal disappears. The signal briefly reappears at $\sim 1800 \mathrm{~h}$ with negative $\bar{f}_{D}$ values corresponding to eastward electric field. In the case of the partial CEJ day of 23 January 1992 (bottom panel), the Doppler shifts observed after the event are initially of low value (negative). They later show a sharp increase in magnitude and by $1800 \mathrm{~h}$, type I echoes are seen as in the case of the 21 January 1992, partial CEJ event.

The observations described up to this point correspond to $104 \mathrm{~km}$ (in terms of the spectral characteristics in Fig. 2 for the four days of observations). Similar features are seen at other altitudes (Figs. 3, 4 and 5) also. The only point of difference is that type I irregularities are not observed at the altitude of $99 \mathrm{~km}$.

Around $1330 \mathrm{~h}$ on 21 January 1992, the signal appears for a short duration of $5 \mathrm{~min}$ at higher altitudes $(>110 \mathrm{~km})$ before disappearing again. During this time the signals (corresponding to westward electric field) are observed at the higher EEJ altitudes of 112, 114 and $117 \mathrm{~km}$ only. This data is recorded at 20-s intervals, and the observed signal is quite strong with a near constant $\bar{f}_{D}$ value of about $+20 \mathrm{~Hz}$ (10-15 dB above noise level) at the higher altitudes above $112 \mathrm{~km}$.

\subsection{Typical Doppler spectra observed on 21 January 1992 in comparison with those observed on the control day}

In this section the unusual radar signatures observed on the partial CEJ day of 21 January 1992 are discussed in detail in terms of the sample Doppler spectra obtained at different times and in relation to the corresponding spectra on the control quiet day. Sample Doppler spectra observed at different times on the control quiet day of 07 January 1992 and the partial CEJ day of 21 January 1992 are shown in Figs. 6 and 7, respectively. The spectra shown here are the received echo power at different times as a function of Doppler shift in the range of -200 to $+200 \mathrm{~Hz}$ observed at the altitude of $104 \mathrm{~km}$. The relative power of the Doppler spectrum is plotted. Each power spectrum is normalized with respect to the peak power at that time. The signal to noise ratio varies in the range of $10-15 \mathrm{~dB}$ before the signal disappears in the afternoon hours on the partial CEJ and the control day. The spectral samples presented here correspond to morning, noon and afternoon times on the two days.

The Doppler spectrum observed on 07 January 1992 at $0909 \mathrm{~h}$ is a broad one, indicating an admixture of both type 


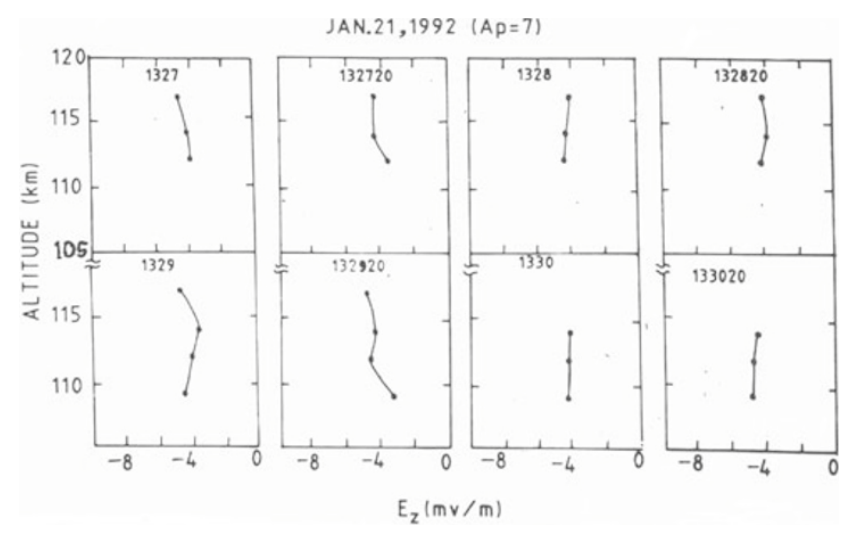

Fig. 9. Altitude profiles of the vertical polarization electric field $E_{z}$ (downward) on 21 January 1992 around $1330 \mathrm{~h}$. These profiles are obtained with a temporal resolution of $20 \mathrm{~s}$.

I and type II spectra, with the spectral peak occurring at $-100 \mathrm{~Hz}$, while on the partial CEJ day of 21 January 1992 and around the same time, the spectrum indicates a strong type I presence with less significant radar power returns at type II Doppler frequencies of approximately $-50 \mathrm{~Hz}$. The presence of type $\mathrm{I}$ is revealed by the peak approximately $-100 \mathrm{~Hz}$, and the broad spectrum encompassing a range of lower frequencies with significant relative power reveals the contribution from type II waves (Viswanathan, 1986). The spectrum at $1330 \mathrm{~h}$ on 07 January 1992 is broader, with a weak type I presence along with significant type II Doppler frequencies. In contrast, on 21 January 1992 at $1330 \mathrm{~h}$, the radar signals are not observed in this altitude region of the EEJ and, hence, only a noise spectrum is shown as a horizontal line in the middle panel of Fig. 7. The noise level $(\mathrm{N})$ is obtained by averaging the power values in the range +150 to $+200 \mathrm{~Hz}$. When the backscattered power is less than $\mathrm{N}+2 \sigma$ (where $\sigma$ is the standard deviation for the positive Doppler frequency band) the spectrum is taken as noise and shown as a horizontal line. At 1630 $\mathrm{h}$ on the control day (as can be seen on the last panel of Fig. 6), the spectrum is entirely type II in nature, with a peak Doppler value of approximately $-50 \mathrm{~Hz}$, indicating reduced value of the eastward electric field in the afternoon hours; the observed spectrum at $1615 \mathrm{~h}$ on the partial CEJ day (last panel of Fig. 7), however, is a nearly symmetrical Gaussian type II spectrum (as no peak is seen near the type I frequency region at approximately $-100 \mathrm{~Hz}$ ). The spectrum is also very narrow (spectral width is small), with a reversed Doppler shift (small $+\bar{f}_{D}$ values) corresponding to the presence of a weak westward electric field.

Figure 8 shows the Doppler spectra observed around 1327 h on 21 January 1992. The spectra are clearly indicative of the eastward drift velocity of the irregularities (and hence the electrons) at higher altitudes of 112-117 km only, in the presence of a westward electric field. The backscattered signal is absent at lower altitudes below $110 \mathrm{~km}$. The spectra shown in Fig. 8 are quiet narrow, with $\bar{f}_{D}$ being +20 $\mathrm{Hz}$ and the estimated $E_{y}$ (Reddy et al., 1987) being around $-0.26 \mathrm{mV} / \mathrm{m}$ (westward). The altitude structure of the vertical polarization electric field $E_{z}$ (which is proportional to the phase velocity of the irregularities) at $\sim 1330 \mathrm{~h}$ on 21

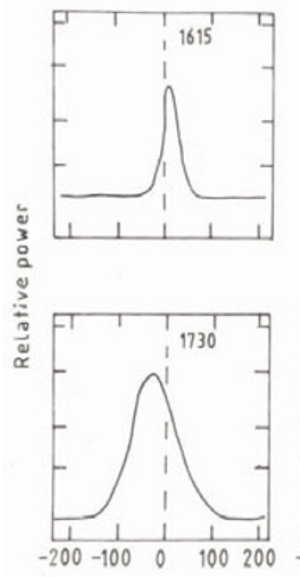

21 JAN. 1992 (AP=7) $104 \mathrm{~km}$
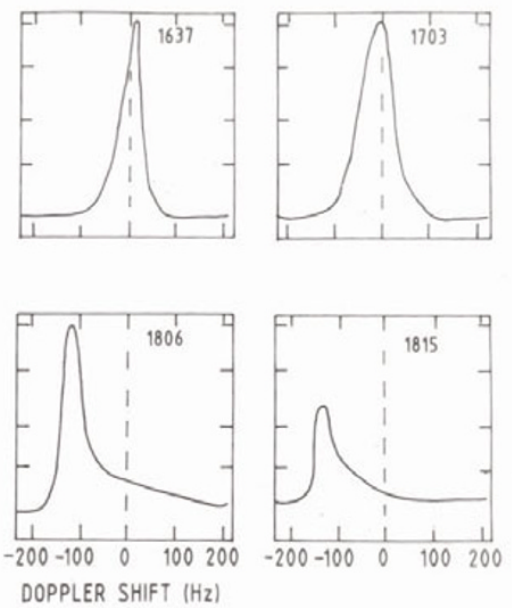

Fig. 10. Doppler spectra obtained at $104 \mathrm{~km}$ between 1615 and $1815 \mathrm{~h}$ on 21 January 1992.

January 1992 is shown in Fig. 9. The profiles are shown at close intervals of $20 \mathrm{~s}$. The negative $E_{z}$ values correspond to the downward field. The profiles significantly differ from those observed during normal electrojet times, when $E_{z}$ values generally show a monotonic increase and decrease on either side of the peak value around $105 \mathrm{~km}$ (Viswanathan, 1986). In addition, $E_{z}$ values (during the CEJ event) are almost constant with altitude, the magnitude being around -4 $\mathrm{mV} / \mathrm{m}$ in all of the profiles shown, whereas the normally observed peak values of $E_{z}$ close to noon hours lie in the range (positive (upward) values) of $10-15 \mathrm{mV} / \mathrm{m}$. However, there are some deviations from this constant value of $-4 \mathrm{mV} / \mathrm{m}$, as can be seen at 1329 and $132920 \mathrm{~h}$.

Figure 10 shows sample Doppler spectra observed at different times at an altitude of $104 \mathrm{~km}$ after the signal reappearance at $1607 \mathrm{~h}$ on 21 January 1992. At the top row of the figure, three spectra (positive Doppler shift) are shown for 1615,1637 and $1703 \mathrm{~h}$, while the bottom row shows spectra (negative Doppler shift) corresponding to 1730, 1806 and $1815 \mathrm{~h}$. At $1615 \mathrm{~h}$, the spectrum is narrow with a low positive Doppler shift, indicating a negative $E_{y}$ value. However, by $1637 \mathrm{~h}$, the spectrum becomes slightly broader in comparison with that at $1615 \mathrm{~h}$. Moreover, the backscattered signal power increases, while the computed $\bar{f}_{D}$ value still remains positive. The Doppler shift is close to zero at $1703 \mathrm{~h}$, with a near symmetrical broad spectrum. Interestingly, at $1730 \mathrm{~h}$, the spectrum (extreme left panel of bottom row of the figure) is broad, with a negative Doppler shift of low values, corresponding to low magnitudes of eastward electric field. It is to be noted in particular that with time, negative Doppler shift values increase from type II to type I frequencies - when the two stream instability sets in-in the presence of the enhanced electric field, as can be seen in the middle and extreme right panels at 1806 and $1815 \mathrm{~h}$ (bottom row of the figure). Moreover, the type I spectrum observed on this day in the late afternoon hours is comparable in magnitude to that observed close to the noon hours when the $E_{y}$ value is typically about $1 \mathrm{mV} / \mathrm{m}$. On $23 \mathrm{Jan}-$ uary 1992 also, type I (negative Doppler shift) spectra are 
observed at these time.

\section{Discussion}

VHF radar observations are analyzed for partial and full CEJ events of 21-23 January 1992 in terms of the Doppler frequency shift measurements of type I and type II irregularities (Fejer and Kelly, 1980) and the backscattered power variations at several altitudes in the EEJ. The observations reveal the differences and common features noticed on the CEJ days and the control quiet day of 07 January 1992.

The reversed Doppler signal observed prior to the maximum depression in $\Delta \mathrm{H}$ (when the magnetic field is significantly positive) for a brief duration of $5 \mathrm{~min}$ at approximately $1330 \mathrm{~h}$ on 21 January 1992 at higher altitudes of $112-117 \mathrm{~km}$ is a new observation. Somayajulu et al. (1994) observed the reversed Doppler corresponding to the westward electric field (during CEJ times) only at altitudes $<112 \mathrm{~km}$. This indicates the presence of negative electron density gradients in association with the westward electric field in the altitude region of $112-117 \mathrm{~km}$, thus satisfying the condition $\Delta \mathrm{N}$. E $>0$ for the generation of type II irregularities (Fejer and Kelley, 1980). At altitudes below $110 \mathrm{~km}$, the gradients and electric fields are not in same direction.

At this time of $\sim 1330 \mathrm{~h}$, distortions in the altitude profiles of the vertical (downward) polarization electric field $E_{z}$ are observed (refer to Fig. 9). The profiles are nearly constant in altitude, with a magnitude of $-2.6 \mathrm{mV} / \mathrm{m}$, in contrast to the normally expected $E_{z}$ profile of a gradual increase followed by a decrease, with a peak value at $\sim 105$ $\mathrm{km}$. Somayajulu et al. (1994) showed the reversals in the drift velocity of the electron density irregularities and distortions in the altitude structure of the EEJ during CEJ occurrences in summer months in the presence of strong blanketing Es layers. They reported that the striking characteristic is the reversal of the irregularity drift velocity at higher (107-112 km) and lower (90-100 km) altitude regions (corresponding to westward electric field) and the normal westward drift (typical of daytime conditions and eastward electric field presence) at the altitudes in between. The observations reported in the present study also provide experimental evidence for the theoretically predicted distortions (Reddy and Devasia, 1981) in the altitude structure of the polarization electric field in the EEJ due to local effects of shearing zonal neutral winds.

During the duration of CEJ, when the radar shows reversed Doppler signals, as shown in the spectra at different times, the $\Delta \mathrm{H}$ values are positive. Reddy et al. (1980a) studied some features associated with the occurrence of CEJ and the lunar phase-dependence of such events using VHF radar measurements of irregularity drift velocities and ground-based magnetometer observations at Trivandrum. They demonstrated that on some occasions $\Delta H$ values do not show the afternoon depression, which is characteristic of a partial CEJ event, even though VHF radar observations indicate the presence of a depression or 'bite-out' in the backscattered signal strength and $\overline{f_{D}}$ values. The implications of such observations on CEJ days bearing a relationship on the lunar phase have been presented in detail in terms of possible distortions due to local wind-generated currents in association with that due to large-scale electric field in the altitude structure of the electrojet.

In the present study, the enhanced $\Delta \mathrm{H}$ values observed during evening times on certain CEJ days coinciding with the appearance of type I waves, as seen by the radar, is a unique observation. Such observations of type I waves in the evening sector have been made only during the CEJ events studied here, and such a feature is not seen on nonCEJ days. This is possibly an indication of unusual tidal influences on CEJ days.

Large phase variability of $\mathrm{Sq}(\mathrm{H})$ has been reported at equatorial latitudes (Sastri, 1982; Last et al., 1976) and mid latitudes (Brown and Williams, 1969), which are likely to be caused by some drastic changes in the tidal winds on certain days. Globally, the duiurnal $S_{1}(1,-2)$ mode seems to be mainly responsible for the generation of dynamo region electric fields necessary to drive the normal quiet day Sq current system. Stening (1995) suggested that changing admixtures of semi-diurnal tidal modes $(2,2),(2,3)$ and $(2,4)$ can cause reversal of the EEJ and that the combination of the current systems associated with these modes can be superimposed over the current system due to $(1,-2)$ mode to produce the observed effects.

With the CEJ-associated changes being detected at higher latitudes also (Stening 1977b, 1995), a system based on global tidal modes is more appropriate to explain the observed features. The present study focuses attention on certain unusual observations made on the CEJ days studied. Further studies using magnetometer, ionosonde and radar observations with better spatial and temporal resolution are necessary to address specific aspects of CEJ in a quantitative manner. Such studies can reveal the possible physical processes responsible for the day-to-day variability in CEJ occurrence.

\section{References}

Ananda Rao, B. G. and R. Raghavarao, Structural changes in current fields of the equatorial electrojet due to zonal and meridional winds, J. Geophys. Res., 92, 2514, 1987.

Brown, G. M. and W. R.Williams, Day-to-day variability of $\mathrm{Sq}(\mathrm{H})$, Planet Space Sci., 17, 455-466, 1969.

Crochet, M., C. Hanuise, and P. Broche, HF radar studies of two-stream instability during an equatorial counter electrojet, J. Geophys. Res., $\mathbf{8 4}$ 5223, 1979.

Fambitakoye, O. P., P. N. Mayaud, and A. D. Richmond, Equatorial electrojet and daily regular variation SR-III. Comparison of observations with a physical model, J. Atmos. Terr. Phys., 38, 113, 1976.

Farley, D. T., A plasma instability resulting in field aligned irregularities in the ionosphere, J. Geophys. Res., 68, 6083, 1963.

Farley, D. T., Theory of equatorial electrojet plasma waves/: New developments and current status, J. Atmos. Terr. Phys., 47, 729, 1985.

Fejer, B. G. and M. C. Kelly, Ionospheric irregularities, Rev. Geophys. and Space Phys., 18, 401, 1980.

Forbes, J. M., Equatorial electrojet, Rev. Geophys. Space Phys., 19, 469, 1981.

Forbes, J. M. and R. S. Lindzen, Atmospheric solar tides and their electrodynamic effects, I, The global Sq current system, J. Atmos. Terr. Phys., 38, 897, 1976a.

Hauise, C., C. Mazaudier, P. Vila, M. Blanc, and M. Crochet, Global dynamo simulation of ionospheric currents and their connection with the equatorial electrojet: A case study, J. Geophys. Res., 88, 253, 1983.

Last, B. J., D. A. Emilia, and A. K. Outhred, AQD occurrence at Adis Ababa, Trivandrum and Alibag, Planet. Space Sci., 24, 567, 1976.

Mariott, R. T., A. D. Richmond, and S. V. Venkateswaran, On quiet-time equatorial electrojet and counter electrojet, J. Geomagn. Geoelectr., $\mathbf{3 1}$, 311, 1979.

Mayaud, P. N., The equatorial counter electrojet-a review of its geomag- 
netic aspects, J. Atmos. Terr. Phys., 39, 1055, 1977.

Omwumechili, C. A., Study of the return currents of the equatorial electrojet, J. Geomagn. Geoelectr., 44, 1, 1992.

Rastogi, R. G., Westward equatorial electrojet during daytime hours, $J$. Geophys. Res., 79, 1503, 1974.

Rastogi, R. G., The equatorial electrojet: Magnetic and ionospheric effects, in Geomagnetism, 3 ed., J. A. Jacobs, Academic Press Limited, London, $453,1989$.

Ravindran, S. and C. A. Reddy, Variation of type I plasma wave phase velocity with electron drift velocity in the equatorial electrojet, J. Geophys. Res., 98, 21581, 1993.

Reddy, C. A., The equatorial electrojet and associated plasma instabilities, J. Sci. Indst. Tes., 36, 580, 1977.

Reddy, C. A., Equatorial electrojet-A review of ionospheric and geomagnetic aspects, J. Atmos. Terr. Phys., 43, 557, 1981.

Reddy, C. A., The equatorial electrojet, Pure Appl. Geophys., 131, 485, 1989.

Reddy, C. A. and C. V. Devasia, Height and latitude structure of electric fields and currents due to local east-west winds in the equatorial electrojet, J. Geophys. Res., 86, 5751, 1981.

Reddy, C. A., V. V. Somayajulu, and K. S. Viswanathan, The lunar phase and the equatorial electrojet, In low latitude aeronomical processes, Proceedings of Symposium, Bangalore, India, May 29-June 9, 1979.

Reddy, C. A., B. T, Vikramkumar, and K. S. Viswanathan, Electric fields and currents in the equatorial electrojet deduced from VHF radar observations - I. A method of estimating electric fields, J. Atmos. Terr. Phys., 49, 183, 1987.

Reid, G. C., The formation of small-scale irregularities in the ionosphere,
J. Geophys. Res., 73, 1627, 1968.

Richmond, A. D., Equatorial electrojet. I. Development of a model including winds and instabilities, J. Atmos. Terr. Phys., 35, 1083-1103, 1973a.

Sastri, J. H., Phase variability of $\mathrm{Sq}(\mathrm{H})$ on normal quiet days in the equatorial electrojet region, Geophys. J. Roy. Astr. Soc., 71, 187, 1982.

Schieldge, J. P., S. V. Venkateswaran, and A. D. Richmond, The ionospheric dynamo and equatorial magnetic variations, J. Atmos. Terr. Phys., 35, 1045, 1973.

Somayajulu, Behavior of harmonic components of the geomagnetic field during counter electrojet events, J. Geomagn. Geoelectr., 40, 111-130, 1988.

Somayajulu, V. V. and K. S. Viswanathan, Radar observations during equatorial counter electrojet events, Indian J. Rad. And Space Phys., 16, 350, 1987.

Somayajulu. V. V., K. S. Viswanathan, K. S. V. Subbarao, and Ligi Cherian, Distortions in the height structure of the equatorial electrojet, J. Atmos. Terr. Phys., 56, 41, 1994.

Stening, R. J., Analysis of contributions to ionospheric dynamo currents from emf's at different latitudes, Planet. Space Sci., 25, 587, 1977a.

Stening, R. J., Magnetic variations at other latitudes during reversed equatorial electrojet, J. Atmos. Terr. Phys., 39, 1071, 1977b.

Stening, R. J., What drives the equatorial electrojet, J. Atmos. Terr. Phys., 57, 1117, 1995.

Viswanathan, K. S., Study of electrodynamics of the equatorial electrojet, Ph. D. thesis, University of Kerala, India, 99-118, 1986.

G. Manju (e-mail: manju_spl@vssc.org) and K. S. Viswanathan 